\title{
The Failure to Provide an Effective Veterinary Service to Sheep in Australia
}

\author{
JAL Maxwell* \\ Katanning Regional Veterinary Hospital, Katanning, WA, Australia \\ *Correspondence author: JAL Maxwell, Katanning Regional Veterinary Hospital, Katanning, WA, Australia; E-mail: berean@westnet.com.au
}

Received: August 08, 2018; Accepted: August 21, 2018; Published: August 23, 2018;

\section{Introduction}

Sheep have been the pre-eminent livestock species in Australia and wool production has been the country's greatest contribution to the world's economy, so why is it that there isn't an effective veterinary service to sheep in place there?

Sheep are not native to Australia and were originally imported; 44 sheep were among the animals transported from Great Britain to the penal colony established on the east coast of Terra Australis in January 1788 http://firstfleetfelowshp.org.au.

The following brief account of the history of wool in Australia is taken from "The Australian Merino" which began;

The Australian Merino...comprised one of the greatest creative expressions of domestic animal species by and for mankind...one of the greatest contributions to the world economy [1].

These original sheep were for human provisions and consisted of fat-tailed native sheep from the Cape of Good Hope, but the primary source of sheep for the first three or four decades of Australia's history were from Bengal, the closest British colony to Australia. The Macarthur family were the first wool sheep breeders in the new colony of New South Wales (NSW) and in 1807 Australian wool first appeared in the English customs returns and in 1811, Samuel Marsden dispatched the first significant shipment of between 4,000 and 5,000 pounds of Australian wool to England.

Wool production followed the development of the colony, beginning in NSW and Van Diemen's Land (Tasmania) and extended as new grasslands were discovered. Legal settlement was followed by illicit occupation into the Port Phillip region (Victoria) with sheep coming from both NSW and Tasmania and from there they travelled west into South Australia (SA) and north into the New England district of NSW on into Queensland (Qld). The "Squatting era" occurred between the 1830s and 1840s and a "Squatter" was an illegal Occupier of crown land beyond the prescribed limits of settlement. By the late 1840 s, the authorities recognized the economic good derived form this activity and issued licences for their sheep runs and tenure. The 1850s saw an influx of immigrants, including miners drawn to Australia by the discovery of gold, and thereafter, the colonies passed "Selection Acts" which provided for the sale of land at auction, forcing squatters to bid against others for the land they had previously controlled by leasehold.
From this time onward, sheep spread throughout the whole continent, including the harsh areas that became known as pastoral regions. Sheep studs were located in the more favourable regions, but commercial flocks were found everywhere and by Federation in 1901, most areas had been settled. During the latter part of the $19^{\text {th }}$ century, Australia rose to become the premier supplier of wool to the world and during the $20^{\text {th }}$ century that position was consolidated. However, the wool industry collapsed during the latter part of the $20^{\text {th }}$ century;

In 2006, Fifteen years after the collapse of the Australian Wool Corporation's Reserve Price Scheme, Australia's Merino studs were selling one-third the number of rams of 1990, over half Australia's professional woolgrowers had ceased growing wool as their main enterprise; the wool fibre's global market share has continued a steady decline since 1991 [2].

\section{Veterinary Literature Review}

The veterinary art has been known since antiquity, but the modern era is considered to have begun in the $18^{\text {th }}$ century with the establishment of university education for veterinarians [3].

Since that time veterinary schools were established everywhere, including Australia, for in 1888, William Tyson Kendall established the Melbourne Veterinary College in conjunction with his private practice in Melbourne [4].

In 1909, this college was absorbed into the veterinary school established at the University of Melbourne. The University of Sydney established a school in 1910; the University of Queensland in 1936 and in 1974, Murdoch established one in Perth [5-8].

During the first half of the $20^{\text {th }}$ century, government veterinarians dominated the profession, whereas practitioners, especially those in rural practice, struggled to survive $[9,10]$. At the time of World War II, there was even talk about nationalisation of the profession $[11,7]$. In 1951, an article on research of sheep disease during the first half of the $20^{\text {th }}$ century was published which demonstrated that most of the significant sheep diseases had been researched about 40 governments, academic and industry veterinarians [12].

In 1958, articles appeared on rural veterinary services highlighting the different roles of the state service and private practice [13] and at the Annual General Meeting (AGM) of the Australian Veterinary Association (AVA) that year, three practitioners spoke on the subject of organising and developing a practice in sheep districts [14]. From Young in NSW, the first speaker said; 
I would say that it is impossible to make a living as a practitioner in a sheep district where, few, if any, studs exist and where there are no other sources of income...in any such practice small animals are the bread and butter of the practitioner.

This speaker thought the future was "precarious" and blamed the government free-service and suggested nationalisation of the veterinary profession $[14,15]$. The second speaker spoke of his experience during three-years developing a practice in the New England region of NSW and he began with;

In a practice specialising in sheep work, the majority of cases concern animals other than sheep.

As a result, he changed the method for charging sheep work from the traditional fee-for service to an annual contract. When he did this, the sheep work increased from $12 \%$ to $24 \%$.

Encouraged, he proposed that three factors were necessary for the conduct of a veterinary practice with sheep: firstly, the industry must be "stable" and "prosperous"; secondly the wool-grower "must be well educated, intelligent and progressive"; and, thirdly, the veterinarian must be able "to render useful service" [16].

From Skipton, in Victoria, the third speaker began;

Practice in a sheep district obviously involves certain difficulties not met with in most dairying districts, and establishment of a practice in any one district, based principally upon the sheep of that district, is unlikely.

\section{And concluded;}

The first rule in practice in a sheep district should be to place little reliance on sheep work...A practice in a sheep district cannot be established without a large amount of cattle work or a good small animal practice or the sale of sheep medicines [17].

In 1959, after listening to what rural practitioners had to say about the difficulties of providing a service to livestock producers, an academic veterinary stated; This is a serious situation that cannot wait indefinitely to be remedied. Have we been fiddling while our farm market of veterinary service has been burning down? [18].

Sixty years ago, Gordon reported that Australia's veterinary profession was not providing a service to the farming community and warned that the opportunity to do so may have already been lost. The next practitioner to venture into sheep practice did so in 1964, described his experience with what he termed the "Whole Farm Approach". After a research career, he spent a short time developing a consulting service in the New England region of NSW, before accepting an academic post. He emphasised the need to examine both animal and farm productivity.

In 1971, when Australia had 100 thousand wool-growers and 180 million sheep, the veterinarian employed by the farmer's co-operative, Gazcos, provided his thoughts on the future of the sheep industry and implications for the veterinary profession [19] stating;

Most of the veterinary work associated with the sheep industry had been carried out by Government veterinarians either in health services or research...practitioners have possibly contributed least of all.
And concluded;

I doubt if we can afford to have duplication which now exists in the rural areas between Government veterinarians and practitioners... This is controversial but it is a problem we have to face [19] (Cole 1971-72).

In 1978, a practitioner spoke at the AGM of the AVA on his experience with a Preventive Medicine/ Animal Production Sheep Consultancy Service in the south-west of Western Australia [20]. In this, and later publications $[21,22]$ (he outlined the research conducted, results achieved and the subsequent failure of the service and demonstrated that the problem providing an effective veterinary service to Wool-growers and sheep-breeders was not due to the service provided, but because the latter did not want to pay for such a service.

Since then, apart from a tribute to Professor Blood [23] and a Post Graduate Foundation Proceedings [24, 25], little has been documented regarding the servicing of sheep by practitioners in Australia.

In 2002, the Australian Government examined the status of the veterinary profession and its services in an enquiry titled "Review of Rural Veterinary Services" [26]. The Review provided a sombre assessment of veterinary services to economic livestock; its assessment of services was accurate, but its recommendations proved ineffective.

In 2007 , it was reported that no more than $12 \%$ of Australia's veterinary effort was devoted to farm animals; in other words, only one in eight of Australia's veterinarians attended livestock [27].

\section{Current research}

In 2015, the author began a post-doctoral thesis to examine the impact of the Frawley Review on Australia's veterinarians. Three areas raised in the review, namely, rural veterinary services, animal quarantine and education, were the subject of the research [28].

\section{Method}

A national on-line survey of Australia's veterinary services was undertaken, whilst, one-on-one, oral history interviews were conducted with quarantine personnel and Deans and Heads, both past and present, of Australia's veterinary schools.

A 40-question, on-line survey was designed and each of Australia's veterinary boards was contacted to seek co-operation in the study. Seven of the eight boards agreed to participate and the survey was posted in February 2016 and closed in June of that year.

\section{Results of the survey}

The number of registered veterinarians in Australia at 30 June 2016 for the seven participating veterinary boards was 9,076 and 555 responses were received to the survey (personal communication, Australasian Veterinary Boards Council).

The mean age of all respondents was 45 years. The mean age for female respondents was 40 years, which was significantly younger than for males which was 53 years. 
Table 1. Respondent Demographics

\begin{tabular}{|l|l|l|}
\hline \multicolumn{1}{|c|}{ Criteria } & Number & Percentages $\mathbf{( 9 5 \% ~ C l )}$ \\
\hline Gender: & & \\
Female & 356 & $64.1(60.0,68.1)$ \\
Male & 199 & $35.9(31.8,40.0)$ \\
Total & 555 & \\
Place of birth: & & $73.5(69.6,77.1)$ \\
Australia & 405 & $26.5(22.9,30.3)$ \\
Overseas & 146 & \\
Total & 551 & $37.9(33.9,42.1)$ \\
Background: & 209 & $62.1(57.9,66.1)$ \\
Rural & 342 & \\
Urban & 551 & \\
Total &
\end{tabular}

Sixty-four percent of respondents were female, $74 \%$ were born in Australia and $62 \%$ grew up in an urban environment.

Table 2. Employment at graduation and at time of survey

\begin{tabular}{|l|l|l|l|l|l|l|}
\hline \multicolumn{1}{|c|}{ Employment } & \multicolumn{3}{|c|}{ At Graduation } & \multicolumn{3}{c|}{ At Survey } \\
\hline & n & $\%$ & $(95 \%$ CI) & n & \% & $(\mathbf{9 5 \%}$ CI) \\
\hline Practice & 463 & 87.5 & $(84.4,90.2)$ & 364 & 68.4 & $(64.3,72.4)$ \\
Government & 32 & 6.0 & $(4.2,8.4)$ & 52 & 9.8 & $(7.4,12.6)$ \\
Teaching / research & 23 & 4.3 & $(2.8,6.4)$ & 48 & 9.0 & $(6.7,11.8)$ \\
Other & 11 & 2.1 & $(1.0,3.7)$ & 68 & 12.8 & $(10.1,15.9)$ \\
Total & & & 529 & 532 & & \\
\hline
\end{tabular}

Eighty-eight percent of respondents stated that they entered practice at graduation, but at the time of the survey $68 \%$ were employed there; $6 \%$ entered government service, but at the time of the survey $10 \%$ were employedthere; $4 \%$ entered research and teaching, but now $9 \%$ were employed there; $2 \%$ were initially classified as "Other or Sundry", whilst now $13 \%$ were employed there. Nine percent of respondents reported that they worked "on-farm".

Table 3. Rural and Urban employment at graduation and at time of survey

\begin{tabular}{|l|c|c|c|c|c|c|}
\hline $\begin{array}{l}\text { Where service } \\
\text { provided }\end{array}$ & \multicolumn{3}{|c|}{ At graduation } & \multicolumn{3}{c|}{ At Survey } \\
\hline & n & $\%$ & $(95 \%$ Cl) & n & $\%$ & $(95 \%$ CI) \\
\hline Rural & 289 & 54.5 & $(50.2,58.8)$ & 147 & 28.3 & $(24.5,32.4)$ \\
Urban & 241 & 45.5 & $(41.2,49.8)$ & 372 & 71.7 & $(67.6,75.5)$ \\
Total & 530 & & & 519 & & \\
\hline
\end{tabular}

Fifty-five percent of respondents initially worked in the country, whilst at the time of the survey $28 \%$ were employed there. Significantly more males commenced work in rural practice than did females, however, at the time of the survey there was no significant difference between the sexes. Eighty-one per cent of males and $84 \%$ of females who worked in rural practice at the time of the survey, began their career there.
Table 4. Comparison of full-time vs part-time and continuous vs discontinuous

\begin{tabular}{|l|c|c|c|}
\hline \multicolumn{1}{|c|}{ Options } & Number & Percentage & $\mathbf{( 9 5 \% ~ C l )}$ \\
\hline Full-time employment & 319 & 58.2 & $(54.9,62.4)$ \\
Part-time employment & 229 & 41.8 & $(37.6,46.0)$ \\
Total & 549 & & \\
Continuous employment & 428 & 78.0 & $(74.3,81.4)$ \\
Discontinuous employment & 121 & 22.0 & $(18.6,25.7)$ \\
Total & 549 & & \\
\hline
\end{tabular}

Fifty-eight per cent of respondents worked full-time during their careers and the proportion of males was similar to that of females. Seventy-eight per cent of respondents worked continuously at their veterinary career; $86 \%$ of males worked continuously, which was significantly higher than that of females at $73 \%$.

Table 5. Satisfaction with various aspects of veterinary science

\begin{tabular}{|l|r|r|r|r|r|r|r|r|}
\hline \multicolumn{1}{|c|}{ Satisfaction } & \multicolumn{2}{|c|}{ Education } & \multicolumn{2}{c|}{ Position } & \multicolumn{2}{c|}{ Income } & \multicolumn{2}{c|}{ Status } \\
\hline & \multicolumn{1}{c|}{ n } & \multicolumn{1}{c|}{$\%$} & \multicolumn{1}{c|}{ n } & \multicolumn{1}{c|}{$\%$} & \multicolumn{1}{c|}{ n } & \multicolumn{1}{c|}{$\%$} & \multicolumn{1}{c|}{ n } & \multicolumn{1}{c|}{$\%$} \\
\hline Completely & 112 & 21.0 & 97 & 18.4 & 50 & 9.4 & 95 & 17.8 \\
Mostly & 269 & 50.4 & 235 & 43.9 & 102 & 19.1 & 182 & 34.0 \\
Generally & 119 & 22.2 & 116 & 21.7 & 162 & 30.4 & 157 & 29.3 \\
Not satisfied & 34 & 6.4 & 87 & 16.3 & 219 & 41.1 & 101 & 18.9 \\
Total & 534 & & 535 & & 533 & & 535 & \\
\hline
\end{tabular}

Six percent of respondents were dissatisfied with their education, $16 \%$ with their work as a veterinarian, $41 \%$ with their income, and $18 \%$ with their social status.

Table 6. Occupational hazards and their consequences

\begin{tabular}{|l|c|c|c|}
\hline \multicolumn{1}{|c|}{ Options } & Numbers & Percentages & $\mathbf{( 9 5 \%} \mathbf{C l )}$ \\
\hline Occupational illness/injuries: & 289 & 54.3 & $(50.0,58.6)$ \\
Yes & 243 & 45.7 & $(41.4,50.0)$ \\
No & 532 & & \\
Total & 84 & 16.6 & $(12.5,21.4)$ \\
Results: & 43 & 14.9 & $(11.0,19.5)$ \\
Impaired capacity & 198 & 68.5 & $(62.8,73.8)$ \\
Cause retirement & 289 & & \\
No incapacity & & & \\
Total & & & \\
\hline
\end{tabular}

Fifty-four percent suffered a work-related Injury or Illness during their career and of those, $17 \%$ reported that it impaired their capacity to perform their duty and $15 \%$ reported that as a result they were leaving veterinary service. 
Table 7. Changes since the Frawley Review

\begin{tabular}{|c|c|c|c|}
\hline Options & Numbers & Percentages & $(95 \% \mathrm{Cl})$ \\
\hline Increase livestock caseload: & & & \\
\hline Yes & 60 & 13.2 & $(10.3,16.7)$ \\
\hline No & 393 & 86.8 & $(83.3,89.7)$ \\
\hline Total & 453 & & \\
\hline Increase livestock income: & & & \\
\hline Yes & 56 & 12.3 & $(9.5,15.7)$ \\
\hline No & 398 & 87.7 & $(84.3,90.5)$ \\
\hline Total & 454 & & \\
\hline Supply problem: & 88 & 19.5 & $(15.9,23.4)$ \\
\hline Demand problem: & 364 & 80.5 & $(76.6,84.1)$ \\
\hline Total & 452 & & \\
\hline Want cheap service: & & & \\
\hline Yes & 363 & 79.8 & $(75.8,83.4)$ \\
\hline No & 92 & 20.2 & $(16.6,24.2)$ \\
\hline Total & 455 & & \\
\hline Treat female vets different: & & & \\
\hline Yes & 310 & 64.6 & $(60.1,68.7)$ \\
\hline No & 43 & 9.0 & $(6.6,11.9)$ \\
\hline No opinion & 127 & 26.5 & $(22.6,30.6)$ \\
\hline Total & 480 & & \\
\hline
\end{tabular}

Since the release of the Frawley Review in 2003 , $87 \%$ and $88 \%$ respectively reported that there had been no increase in caseload or income derived from livestock and $80 \%$ of respondents reported that the problem with rural veterinary service was that farmers did not utilise the service, whilst the balance considered the problem to be the service offered.

That is, it was a demand problem not a supply problem. Eighty percent of respondents reported that farmers shop around for the cheapest veterinary service and $65 \%$ reported that farmers treated female veterinarians differently than their male colleagues.

\section{Discussion}

In this survey, $6 \%$ of registered veterinarians responded, so bias is possible and the results may not accurately reflect the views of the whole Australian veterinary population. Further, as the mean age of respondents was 45 years, it is likely that the responding cohort was generally older and represented presumably more experienced graduates than non-respondents.

The mean age of female respondents (40 years) was significantly younger than for males (53 years). This was not surprising given the change in the gender distribution of veterinary students and graduates that have occurred over the past 20 to 30 years [26-28].

In this survey, two-thirds of respondents had an urban background and it is likely this is partly responsible for their preference to work in urban environs in practices predominantly servicing companion animals. The limited attraction of rural service and the change in location from rural to urban environments by veterinarians as they age has been highlighted in the work of Heath.

At the time of graduation, significantly more male survey respondents entered rural service than females, but at the time of the survey there was no significant difference in the proportion of males and females who had remained in rurally based practices. In contrast, and not surprisingly, very few respondents who began their career in urban service, ventured into rural service later in their careers.

At graduation the majority of respondents (88\%) entered private practice with the balance distributed between government service, academia, industry and this is consistent with the findings of others $[27,21]$

At the time of the survey, $68 \%$ of the respondents were in private practice and those who have changed had primarily moved into the "other" categories. This work may be less stressful than private practice and perhaps more interesting, as practice can become routine.

At the time of the survey, slightly more than half $(58 \%)$ of the respondents worked full-time and approximately three-quarters of these had worked continuously as a veterinarian since graduating. This contrasts with earlier eras where most graduates worked as veterinarians all of their working life $[29,13,21]$.

In this sample, less than $10 \%$ of respondents performed veterinary work on-farm, which is in marked contrast to much of the $20^{\text {th }}$ century, when many government veterinary officers and private practitioners functioned on-farm $[13,21]$.

Dissatisfaction with various aspects of veterinary life was canvassed in the survey and $6 \%$ were dissatisfied with undergraduate education, $16 \%$ with work as a veterinarian, $41 \%$ with the income they received, and $21 \%$ with the status achieved as veterinarians. In an earlier study, dissatisfaction with various aspects of their life as students and then as veterinarians, were recorded for WA veterinarians [21]. These results need sober reflection, as they indicate a relatively high level of dissatisfaction with life, income and status as a veterinarian in Australia.

More than half of the survey respondents suffered an injury or illness during their career as veterinarians, with $17 \%$ of these stating it affected their capacity to function and $15 \%$ stating that it would lead to their leaving the occupation of a veterinarian. In a previous study of WA veterinarians, $50 \%$ incurred a major physical injury or disease during their career and of these 59\% stated that it had impaired their performance as a veterinarian and $20 \%$ considered leaving practice as a result [21].

The Frawley Review was commissioned for a number of reasons, one being because Australia's animal health system was being directed towards companion animals instead of production animals and another being that both government veterinary services and rural practices were unlikely to be sustained [26]. Frawley concluded that this would only be reversed if the earning opportunities for rural practice were improved and a better balance in teaching of all animal species could be achieved. There needed to be a significant increase in demand for private practice services by livestock producers and, 
to stimulate demand, Frawley made recommendations which they considered could be helpful. However, unless there was a significant increase in the demand for rural veterinary services, the situation would not improve.

As relatively few livestock producers utilised veterinary practitioners on a regular basis, from the 1970s most rural practices turned to servicing companion animals to remain viable [26, 27]. This survey supports those observations.

The survey respondents reported that since the Frawley Review there had been no increase in either case-load or income from economic livestock. This does not apply to those few rural practices in Australia that provide speciality services for livestock.

The results of the survey, together with those from the oral history interviews were analysed in the thesis and alternatives were discussed. This research led to the questioning of the currently models being used in veterinary science; the models may have outlived their usefulness and for there to be a future for veterinarians in Australia, new models may need to be created.

\section{Conclusion}

Why is it that during the 130-year (1888 to 2018) history of educating veterinarians in Australia, they have failed to provide a service which wool-growers valued? Is it because veterinarians did not provide the right service or because wool-growers do not want to pay for veterinary services? Is it a supply problem or a demand problem?

My analysis is that both are to blame - veterinarians do not provide a service wool-grower's value and wool-growers don't want to pay for a service which they consider they are entitled to! The collapse of Australia's wool industry has been described;

In the mid twentieth century the Australian wool-growing industry was the greatest wool economy the world had ever seen. It was the backbone of the nation's economy for 120 years, being the nations largest export earner and wealth-builder for all but a decade of that period... Then, in a little over two decades at the end of the twentieth century, the wool industry self-destructed [30].

This collapse has been accompanied by further contraction of veterinary services to sheep and other livestock producers. Frawley was a watershed moment for Australia's veterinary profession, but, unfortunately, that opportunity was not acted upon by this country's veterinary profession [31-35]. Perhaps we are too late, for today veterinarians are little interested in providing a service to economic livestock and Australia has turned its back on agriculture in its search of a new identity.

\section{References}

1. Massy C (2007a) Introduction. In: The Australian Merino: The Story of a Nation. Random House Australia P/L, Sydney: xvii.

2. Massy C (2007b) Wool growing and Merino Breeding after 1950. In: The Australian Merino: The Story of a Nation. Random House Australia P/L, Sydney: 1054.

3. Gunn RMC (1927) Veterinary education. Australian Veterinary Journal 2: 44-47.

4. Albiston HE (1951) Veterinary Education in Victoria. Australian Veterinary Journal 27: 253-257.

5. Anon (1925a) The Veterinary Schools of Australia. I. The Sydney University Veterinary School. Australian Veterinary Journal 1: 40-41.
6. Anon (1925b). The Veterinary Schools of Australia. II. The Melbourne University Veterinary School. Australian veterinary journal 1: 75-77.

7. Anon (1941) Nationalization of the Veterinary Profession. Australian Veterinary Journal 17: 2-3.

8. Clarke WT and Grandage J (2005). Early history of the Murdoch Veterinary School. Australian Veterinary History Record 43: 10-24.

9. Stewart JD (1913). Presidential Address. Australian Association for the Advancement of Science: 14th Meeting. Melbourne. XIV: 695-702.

10. Albiston HE (1947) Rural Veterinary Service. Australian Veterinary Journal 22: 78.

11. Bull LB (1938) Possible Developments in the Organisation of Veterinary Services: A National Veterinary Service in Australia. Australian Veterinary Journal 14: 222-226.

12. Bull LB (1951). The Study of Etiology and Control of Sheep Diseases in Australia during the first half Century, 1900-1950. Australian Veterinary Journal 36: 237 245 .

13. Needham NA (1958) Establishment and Maintenance of Veterinary Services in Rural Areas. Australian Veterinary Journal 34: 51-53.

14. Webster W (1958) Veterinary Practice in Rural Areas. Australian Veterinary Journal 34: 48-50.

15. Cole AR (1958) Organisation of veterinary practice in sheep district. Australian Veterinary Journal 34: 423-427.

16. Osborne HG (1958) The development of a veterinary practice in a sheep district. Australian Veterinary Journal 34: 428-431.

17. Taylor PF (1958). The organization of veterinary practice in a sheep district. Australian Veterinary Journal 34: 432-435.

18. Gordon HMcL (1959) Veterinary education. Australian Veterinary Journal 35: 64.

19. Cole V (1971-2) The future of the sheep industry. Implications for the veterinary profession. Victorian Veterinary Proceedings 1971-72

20. Maxwell JAL (1978) A Preventive Medicine - Animal Production service in Western Australia. Proceedings 55th Annual Conference of the Australian Veterinary Association. Sydney 55: 72-73.

21. Maxwell JAL (2008) A short history of rural veterinary practice in Western Australia: 1964 to 2007. Australian Veterinary History Record 52: 13-24.

22. Maxwell JAL (2009) Rural veterinary practice in Western Australia: 1964 to 2007. Murdoch University Veterinary Faculty. PhD Thesis 1-233.

23. Hughes KL (1985) Editor. Proceedings of Internationals Conference on Veterinary Preventive Medicine and Animal Production. Melbourne, Australian Veterinary Journal.

24. Bell KJ (1988) The future direction for private veterinary service to the sheep industry. Proceedings 110: Sheep Health \& Production, Sydney. Post Graduate Committee in Veterinary science, University of Sydney. 110: 135-145.

25. Abbott KA (1988) Financial Analysis on Farms. Proceedings 110: Sheep Health \& Production, Sydney. Post Graduate Committee in Veterinary Science, University of Sydney.110: 249-278.

26. Frawley PT (2003) Review of Rural Veterinary Services. Department of Agriculture, Fisheries \& Forestry. Commonwealth of Australia 1-109.

27. Heath T (2007) Where have all the planners gone? Aust Vet J 85: 435-436. [crossref]

28. Maxwell JAL (2018). Australia's Veterinarians and the Frawley Review of 2002. Murdoch University Veterinary Faculty. DVetMedSc Thesis: 1-218.

29. Niederer SL (1958) The Establishment and Maintenance of a Rural Veterinary practice. Australian Veterinary Journal 34: 54-56.

30. Massy C (2011) Introduction. In: Breaking the Sheep's Back. The shocking and true story of the decline and fall of the Australian wool industry. University of Queensland Press, St Lucia, p xxi.

31. Hall RA (1963) Government and private Practitioner Veterinary Service in New South Wales. Australian Veterinary Journal 39: 105-107

32. Johnstone IL (1966) An example of whole farm consultation in Australia. $N$ Z Vet $J$ 14: 155-160. [crossref]

33. Maxwell JAL, Costa ND, Layman LL and Robertson ID (2007) Rural veterinary services in Western Australia: Part B. Rural Practice. Australian Veterinary Journal 86: 74-80.

34. Meldrum GK (1963) Government and Private Practitioner Veterinary Services in Tasmania. Australian Veterinary Journal 39: 327-329.

35. Smith WS (1963) Government and Private Practice Veterinary service in South Australia. Australian Veterinary journal 39: 102-104.

\section{Citation:}

JAL Maxwell (2018) The Failure to Provide an Effective Veterinary Service to Sheep in Australia. Integr J Vet Biosci Volume 2(3): 1-5. DOI: 10.31038/ IJVB.1000114 